\title{
Neighbourhood alcohol availability and gonorrhea rates: impact of social capital
}

\author{
Katherine P. Theall ${ }^{1}$, Richard Scribner ${ }^{1}$, Bonnie Ghosh-Dastidar ${ }^{2}$, Deborah Cohen ${ }^{2}$, Karen \\ Mason $^{1}$, Neal Simonsen ${ }^{1}$ \\ ${ }^{1}$ Louisiana State University, School of Public Health, New Orleans, LA, USA; ${ }^{2}$ RAND Corporation, Santa \\ Monica, CA, USA
}

\begin{abstract}
Social capital and income inequality have been proposed as important mediators of the relation between the material environment and health outcomes. We determined whether indicators of social capital are (i) associated with neighbourhood gonorrhea rates, and (ii) mediate the relation between alcohol outlet density and gonorrhea rate. Longitudinal analyses of age- and sex-adjusted gonorrhea cases reported from 1990 to 1996 in the 445 census tracts affected by the 1992 civil unrest in Los Angeles, California was conducted. The role of alcohol outlets was assessed both as tracts with surrendered off-sale outlets due to the civil unrest and annual off-sale alcohol outlet density rates. Tract level voting rates were used as one indicator of social capital, while neighbourhood structure conducive to social organization was used as another. Neighbourhoods with greater voting over time and greater endogenous social organization experienced 1.9 and 67.2 fewer gonorrhea cases per 100,000. Results also reveal a partial mediating role of social capital on the relationship between alcohol outlet density and gonorrhea rate. The alcohol environment may have a direct or partially mediated role in infectious disease outcomes such as gonorrhea. Our findings support the importance of continuing controls and limits on off-premise alcohol outlet density, as a potential means of reducing gonorrhea rates and increasing social capital.
\end{abstract}

Keywords: gonorrhea, alcohol outlets, social capital, neighbourhood, deprivation, California.

\section{Introduction}

The impact of neighbourhood environment, including alcohol outlet density, on health outcomes may be due to a number of factors at both individual and community levels. Given the complex relationship between neighbourhood environment and health status, the focus on mechanisms that explain why neighbourhood context may play a role in population and individual health and mortality has come into focus in both sociological and public health literature (Sampson et al., 2002). Social environments

Corresponding author:

Katherine P. Theall

Louisiana State University, School of Public Health

1615 Poydras St., Suite 1400

New Orleans, LA 70112, USA

Tel./Fax: +15045685936

E-mail: kthea1@lsuhsc.edu may come to affect health through stressful neighbourhood conditions as well as availability of resources from social relationships. Structural characteristics such as socio-economic composition, racial/ethnic composition, deprivation, stressful social conditions such as violent crime, and social relations/engagement and how individuals adapt to stressful environments may have an impact on morbidity and mortality and may be a reflection of neighbourhood disorder (Sampson and Raudenbush, 1999; Pickett and Pearl, 2001; Macintyre et al., 2002). Previous studies indicate that deteriorated neighbourhoods characterized by boarded up homes have higher rates of gonorrhea, premature mortality, and premature mortality from homicide and heart disease (Cohen et al., 2000, 2003a,b). The density of neighbourhood alcohol outlets, one potential marker of social disorder in a neighbourhood, has been associated with a variety of negative health outcome 
including homicides, assault, motor vehicle fatalities and gonorrhea rates (Scribner et al., 1994, 1998, 1999; Gruenewald and Ponicki, 1995; Gorman and Speer, 1997; MMWR, 2000).

Signs of neighbourhood physical and social disorder are often indicative of a breakdown of order, social control and social capital in the community. Social capital has been inversely associated with alcohol-related outcomes (Granfield and Cloud, 2001; Lindstrom, 2005; Weitzman and Chen, 2005), including gonorrhea and other sexually transmitted infections (Holtgrave and Crosby, 2003), and has been hypothesized as a potential pathway through which the neighbourhood environment may influence health outcomes. Social capital is often defined as those features of social life and structure (i.e. social networks, norms of reciprocity, and trust in others) that facilitate cooperation for mutual benefit (Putnam et al., 1993). Most public health research on social capital refers to the original definitions of Bourdieu (1986), Coleman (1990), and Putnam (2000) that characteristically include two components of social capital - a structural and a cognitive component - that represent the norms and networks that enable people to act collectively. The structural component of social capital includes aspects such as networks, connectedness, associational life and civic participation. The cognitive component includes aspects such as perceived support, trust, social cohesion and perceived civic engagement. Social capital has also been theorized as having both horizontal and vertical dimensions, each with its own forms of cognitive and structural influences (Szreter and Woolcock, 2004).

Despite numerous critiques, social capital is still regarded as an important concept in understanding health disparities and poorer health (Woolcock and Narayan, 2000; Szreter and Woolcock, 2004; Ziersch et al., 2005; Poortinga, 2006). The health benefits of social capital are achieved at the neighbourhood or individual levels through information resources and diffusion, social influence and control and social solidarity. Communities with higher levels of social capital are often thought of as cohesive and thriving communities. While the effects of social capital may have individual-level consequences (e.g. access to information or other goods and services, sense of belonging and social support), the construct of social capital itself is a collective phenomenon (Lochner et al., 1999; Harpham et al., 2002; Subramanian et al., 2003, 2005). Defined in this way - as a context (e.g. social network) in which individuals are embedded - paves the way for research into how the social and physical environment can influence social capital by shaping social networks. In fact, a number of studies have explored the relationship between the environment and social networks (Sampson and Groves, 1989; Freeman, 1992; Sampson et al., 1997; Cattell, 2001; Leyden, 2003; Carpiano, 2006). For example, Leyden (2003) observed that walkable, mixed-use neighbourhoods (i.e., more "traditional" neighbourhoods that allow residents to perform daily activities without the use of a car) may encourage the development of social networks given that residents are more likely to know their neighbours, resulting in trust and social engagement (Leyden, 2003).

In light of previous critiques on social capital, our research views the social network existing within a community as the source of social capital from which all other consequences are derived. The existence of a social network is evidenced as either a direct measure of that network (e.g. network analysis) or as the aggregate of individual and organizational ties. Figure 1 summarizes these relations.

We hypothesize that social capital (including its sources and consequences) mediates the relationship between the neighbourhood alcohol environment and health outcomes. In previous research, we found that a change in the material environment, measured as a reduction in the number of off-sale alcohol outlets, was associated with an increase in one consequence of social capital-civic engagement (Scribner et al., 2007). Neighbourhoods with neighbourhood structures are more conducive to social organization and therefore social capital were also more likely to experience an increase in voting over time. Results support the hypothesis that a change 


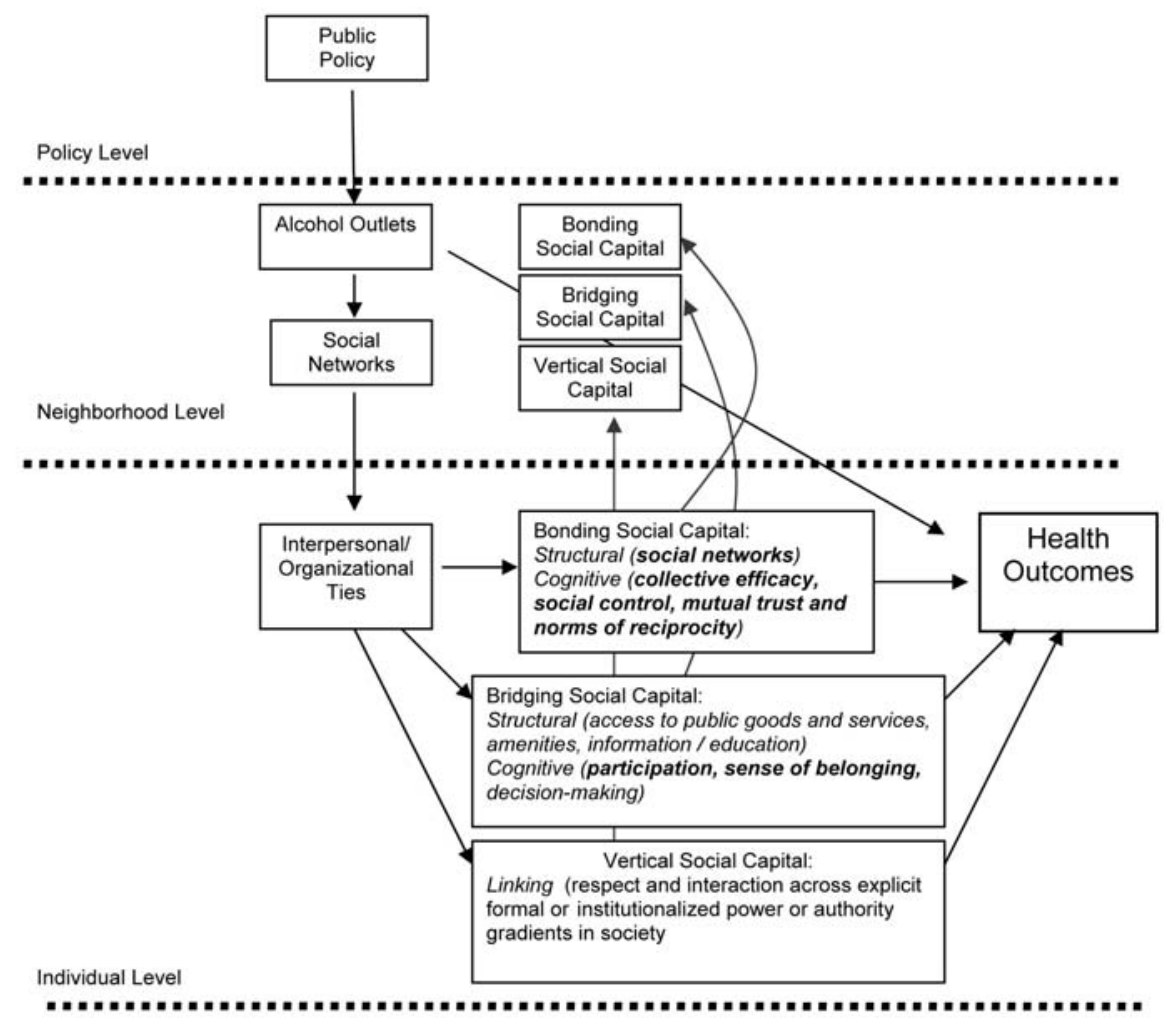

Fig. 1. Conceptual model of off-premise alcohol outlets, social capital and health outcomes.

in the neighbourhood alcohol environment may lead to changes in social capital, likely through its impact on social networks.

In this study we sought: (i) to determine whether indicators of social capital are associated with neighbourhood gonorrhea rates, and (ii) to test our hypothetical model that the relationship between alcohol outlet density and gonorrhea rate is mediated in part by indicators of social capital. We have previously shown that a loss of alcohol outlets was associated with reductions in gonorrhea rates in surrounding neighbourhoods (Cohen et al., 2006). If alcohol outlets are just a proxy for factors such as lower social capital or poverty (assuming they are associated with gonorrhea) or if these contextual factors are stronger predictors of gonorrhea, then no independent relationship between alcohol outlets and gonorrhea should be found when these factors are controlled.

A "natural experiment", precipitated by an abrupt change in the density of alcohol outlets across several communities in Los Angeles county following the 1992 civil unrest, provided a unique opportunity to study the proposed hypotheses. After the verdicts that acquitted the police officers accused of beating Rodney King, riots in Los Angeles destroyed many buildings and commercial businesses. The civil unrest resulted in 53 deaths, 2,325 reported injuries, more than 600 buildings completely destroyed by fire and approximately 735 million US\$ in total damages (Evans, 1993). In the wake of the riots 279 liquor licenses were surrendered in the City of Los Angeles, primarily in south central Los Angeles, an area with a high rate of poverty and a high proportion of minority residents. Community mobilization prevented at least 40 offpremise alcohol outlets from re-opening and many were forced to reopen in other locations (RobinsonJacobs, 2002). We add to previous research on alco- 
hol outlet density and neighbourhood gonorrhea rates (Cohen et al., 2006), expanding on existing study data by considering the role of social capital in the relationship between alcohol outlet density and gonorrhea rates.

\section{Materials and methods}

\section{Sample}

The 1992 civil unrest occurred over a large area of south central Los Angeles. In the present study we include only those specific census tracts affected by civil unrest, thereby controlling for a possible global effect of the unrest on outcomes - that is, that any measured effect associated with the change in neighbourhood environment should be independent of any global effect of the civil unrest. To define the study area in this manner we used a definition established by the Rose Institute which has been used in a number of economic studies of the civil unrest (Hubler, 2002). A total of 480 census tracts lay within the unrest region. The study tracts contain 2,641,320 people, of whom $48 \%$ are Hispanic and $27 \%$ were Black in the 1990 census. A total of 2,240 unique addresses were damaged in the 1992 civil unrest, while 144 tracts had one or more offpremise liquor outlet licenses after the unrest whose license was surrendered. The majority of the damaged addresses were commercial businesses.

Of the 480 census tracts, 35 were excluded from statistical analyses due to low population estimates (i.e. $\leq 500$ individuals) and therefore unstable gonorrhea rates, leaving a total of 445 tracts.

\section{Data sources}

Annual counts of gonorrhea were obtained from the Los Angeles County Department of Health, while annual counts of liquor outlet licenses came from the California Department of Alcohol Beverage Control (ABC). A list of outlets that surrendered their licenses $(\mathrm{ABC})$ and a list of riot-damaged stores as a result of the 1992 Los Angeles civil unrest were also obtained. Alcohol outlets were classified based on their license to sell alcohol onpremise (bars and restaurants) or off-premise (liquor stores, grocery stores and convenience stores) using license codes provided by the ABC. Information on damaged buildings came, directly or indirectly (Ong, 1993) from four different sources: (i) the Los Angeles City Department of Building and Safety, (ii) the Korean Central Daily, (iii) the California Insurance Commission, and (iv) the Compton Department of Building and Safety. Biannual voter registration data for the state of California was available from the University of California, Berkeley, Institute of Governmental Studies for 1990, 1992, 1994 and 1996 and interpolated for remaining years as the average between prior and subsequent years.

All unique address listings were geo-coded and mapped to the 1990 census tract areas, and individual data sources were matched by census tract. The annual estimates of population distributions by age, race and gender were obtained from the Los Angeles County Department of Health Services, with actual counts available for 1990 and 1995 and interpolated values for the other years. The remaining predictors were obtained from 1990 U.S. Census data for Los Angeles county.

Individual residences, age, gender and race/ethnicity of persons diagnosed with gonorrhea were obtained and addresses geo-coded then aggregated by census tracts for analysis. Over $80 \%$ of addresses were matched using ArcView 3.2 GIS software (ESRI Inc, Redlands, CA) along with Los Angeles county TIGER street files from the 2000 census. Addresses that the computer was unable to match were hand placed with the help of an Internet mapping site (Mapquest) and a Thomas Guide map book.

\section{Gonorrhea rates}

The outcome of interest in this study was annual age- and gender-adjusted gonorrhea rate (1990$1996)$ per 100,000 at the census tract level, calculated using direct standardization. 


\section{Alcohol outlet density}

Measures of alcohol exposure included surrender of off-premise liquor outlet license following the May, 1992 civil unrest, the percentage of off-premise liquor outlet licenses surrendered and annual offpremise or off-sale alcohol outlet density from 1991 to 1996. From data on outlet surrenders two tractlevel measures were incorporated in the analysis to assess the effect of decreased alcohol availability caused by outlet destruction associated with the 1992 civil unrest. The measures include: (i) percent surrendered - a continuous measure of the percentage of all off-sale outlet licenses that were surrendered in a tract (i.e. 0.00 to 1.00 ), and (ii) surrender tracts - a dichotomous measure of census tracts that did and did not have outlet licenses surrendered due to destruction. We measured surrendered off-premise alcohol licenses by computing the ratio of the number of off-premise liquor outlet licenses surrendered in 1992 to the total number of off-premise liquor outlet licenses in the tract in 1991 just prior to the civil unrest.

Annual alcohol outlet density was measured as the ratio of the number of off-premise liquor outlets to the number of miles of roadway in each tract based on 1990 geographic census data. The number of outlets per roadway mile for each census tract was used to quantify exposure to alcohol outlets, although the number per population and per square mile area were also calculated and compared for consistency.

\section{Social capital}

Civic engagement was utilized to monitor changes in social capital over time (Putnam et al., 1993). Although civic engagement is a consequence of social capital, we believe it is a sensitive measure of change in the local social network following the civil unrest. Civic engagement was measured as the percentage of residents in each census tract registered to vote who actually voted in a given year. Because voter registration data was available for the years
1990, 1992, 1994 and 1996, values for remaining years were defined as the average voting rate between the year prior to and following the missing year (e.g. 1991 was taken as the average voting rate using years 1990 and 1992) to get an annual estimate of voter participation. While we include only one indicator of social capital, there are numerous ways to measure social capital, both at the individual (e.g. survey) and aggregate levels (Harpham et al., 2002). Measurements at both levels have improved dramatically over time, particularly at the individual level, to incorporate both cognitive and structural components. Moving towards a measure that captures the complete and extremely complex essence of social capital in all its forms (e.g. bonding, bridging, vertical, horizontal and linking) remains challenging (Harpham et al., 2002).

\section{Endogenous social organization}

Because it is important to distinguish social capital and the development of social capital from the concept and development of social networks and their consequences such as social support (Harpham et al., 2002), we also examined specific aspects of neighbourhood structure that may influence the development of social networks and organizations and, in turn, social capital in a community (Sampson et al., 1997, 1999; Sampson, 2003; Metro Chicago Information Center, 2005). Social network formation, however, does not always equate to the development of positive social capital, although in this study we view endogenous social organization as a beneficial community characteristic that could lead to positive social capital development. Indicators of neighbourhood structure were based on 1990 US census estimates. An index was created and included two different sub-components: interaction potential and stability. These were taken from the larger Metropolitan Information Center's Community Vitality Index (Metro Chicago Information Center, 2005), and have been used by others to examine neighbourhood structure conducive to the development of positive consequences 
of social capital, namely social control, collective efficacy and lower neighbourhood crime rates (Bursik, 1988; Sampson et al., 1997, 1999; Sampson, 2003). The scale demonstrated a fairly high degree of reliability in this sample (Cronbach's alpha $=0.83$ ).

Interaction potential included: (i) neighbour interaction, defined as the percentage of households that are not linguistically isolated (assuming that a common language is vital to a community's capacity to participate fully in the larger social and economic structure); (ii) social support, defined as the percentage of households with more than one adult (assuming that social support systems of individuals in single-person households may be weak, making these individuals less likely to be involved in or committed to their geographic communities); and (iii) availability, measured as the percentage of households with one or more adults not in the labor force (with the assumption that these households are ones where someone may have more time to invest in building relationships in the community).

Stability included: (i) mobility, defined as the percentage of all households that reported that they moved in the past five years, inversely coded (assuming that neighbourhood structure contributes to neighbourhood connectedness, which may increase social capital); and (ii) immigration, measured as the percentage of foreign-born residents who entered the US and their specific census tract within five years of the 1990 US Census, also inversely coded (assuming immigration results in significant social and cultural adjustments that may hamper development of social cohesion).

\section{Additional covariates}

Additional covariates included in our analysis were (1) percentage Black, (2) percentage Hispanic, (3) percentage male, (4) percent of population between the ages of 15 and 44 years, (5) percent of population with less than high school education, (6) baseline adjusted gonorrhea rate, (7) an index of socio-economic status, computed by averaging stan- dardized values of the 1990 census measures: median income, percent of population with education level less than high school and percent unemployed in the tract, and (8) physical damage in neighbourhood. The first four covariates were annual estimates available for the years 1990-1996 and were included due to their association with gonorrhea. As annual estimates, they permit longitudinal models to control for endogenous effects. For example, it is possible that changes in social capital are the result of the movement of high or low social capital populations into or out of particular study tracts over the course of the observation period. Baseline gonorrhea rate was from 1990. Physical damage was measured as a binary indicator of any damage in the tract due to the civil unrest. We also derived a measure of damage density, calculated as the ratio of the number of unique addresses damaged in the 1992 civil unrest to the proportion of land in the tract used for commercial purposes.

\section{Statistical analyses}

In all analyses, the unit of analysis was the census tract. To examine the association between social capital measures on gonorrhea rates and their mediating role on the impact of alcohol outlet surrenders on gonorrhea rates over time, we used multi-level longitudinal growth models performed with PROC Mixed in SAS (Littell et al., 1996; Singer, 1998), with level-1 representing the within tract variation and level-2 between tract variation in parameters as a function of tract-level covariates (characteristics) and interactions of time with tract-level covariates. This model includes both a random intercept and a random slope over time for each tract. All of the variables including time were centered at their respective 1992 means. In all models, we controlled for all available baseline and time-varying covariates to account for selection effects. We ran models with and without social capital indicators to examine their mediating role. The effects of any spatial autocorrelation in the data was taken into account using PROC Mixed with repeated measures of 
spherical clustering, based on the state plane coordinate system in miles, using a 2.5 mile lag distance. This procedure adjusted the standard errors and significance tests to account for any inflation or deflation due to geographical clustering of GC rates.

Moran's $I$ tests for global clustering were also conducted on the overall tract-level gonorrhea rate and on adjusted rates (i.e. the residual) based on the aforementioned models from PROC Mixed, to determine whether or not spatial clustering persists after accounting for shared social structure and the important covariates - alcohol outlet density and indicators of social capital. To further quantify spatial structure in the gonorrhea residuals we decomposed Moran's I into a local indicator of spatial association or LISA statistic and this was mapped in $\mathrm{GeoDa}^{\mathrm{TM}}$ (Anselin, 2005).

\section{Results}

Table 1 summarizes the predictors used in the models and describes the demographic characteristics of the 480 tracts in Los Angeles County included in the unrest area. Among the tracts, the average number of pre-riot off premise alcohol outlets per road mile was 0.77 . One-third of tracts surrendered at least one outlet following the unrest and the average percent of off-premise liquor outlet licenses surrendered was $10 \%$. The average proportion of tracts that reported any damage due to the civil unrest was $65 \%$. The pre-riot (1990) percent voting was $33 \%$, while the average post-riot percent voting was approximately $47 \%$.

Pearson's product moment correlation coefficients between gonorrhea rate and social capital indica-

Table 1. Demographic characteristics of unrest area tracts in Los Angeles county and association with baseline (1991) gonorrhea rate.

\begin{tabular}{|c|c|c|c|c|}
\hline & Mean & SD & Range & $\begin{array}{l}\text { Correlation with } \\
\text { gonorrhea rate }^{\mathrm{a}}\end{array}$ \\
\hline \multicolumn{5}{|l|}{ Time level variables } \\
\hline $\begin{array}{l}\text { Mean 1988-1991 gonorrhea rate per 100,000 } \\
\text { Mean 1993-1996 gonorrhea rate per 100,000 } \\
\text { Mean \% African American } \\
\text { Mean \% Hispanic } \\
\text { Mean \% Asian } \\
\text { Mean \% Male } \\
\text { Mean \% 15-44 years } \\
\text { Mean \% less than high school education }\end{array}$ & $\begin{array}{r}595.4 \\
193.9 \\
26.9 \\
47.8 \\
7.9 \\
49.9 \\
51.9 \\
45.7\end{array}$ & $\begin{array}{r}714.3 \\
211.5 \\
28.0 \\
28.8 \\
11.5 \\
4.6 \\
7.3 \\
20.8\end{array}$ & $\begin{array}{r}0.0-5316.0 \\
0.0-1886.2 \\
0.0-94.0 \\
3.0-98.0 \\
0.0-81.0 \\
38.0-96.0 \\
16.0-98.0 \\
4.0-86.0\end{array}$ & $\begin{array}{r}\mathrm{NA} \\
\mathrm{NA} \\
0.760 \ddagger \\
-0.292 \ddagger \\
-0.370 \ddagger \\
-0.064 \\
-0.373 \ddagger \\
0.052\end{array}$ \\
\hline $\begin{array}{l}\text { Mean } 1990 \text { pre riot \% voting } \\
\text { Mean } 1993-1996 \text { post riot \% voting }\end{array}$ & $\begin{array}{l}33.0 \\
45.6\end{array}$ & $\begin{array}{l}6.8 \\
9.8\end{array}$ & $\begin{array}{r}18.0-70.0 \\
14.0-100.0\end{array}$ & $\begin{array}{l}-0.118 \ddagger \\
-0.281 \ddagger\end{array}$ \\
\hline \multicolumn{5}{|l|}{ Tract level variables } \\
\hline Mean 1990 neighbourhood structure index score/endogenous social organization & 0.16 & 0.43 & $-1.5-1.0$ & $0.132 \dagger$ \\
\hline $\begin{array}{l}\text { Mean } 1990 \% \text { below poverty } \\
\text { Mean } 1990 \text { SES }^{\mathrm{b}} \text { index ( } \% \text { < high school, median income, \% unemployed) }\end{array}$ & $\begin{array}{r}23.4 \\
-0.76\end{array}$ & $\begin{array}{l}12.9 \\
0.73\end{array}$ & $\begin{array}{r}0.0-93.0 \\
-2.5-1.7\end{array}$ & $\begin{array}{r}0.403 \ddagger \\
-0.252 \ddagger\end{array}$ \\
\hline $\begin{array}{l}\text { Any damage in } 1992 \text { civil unrest (binary) } \\
\text { Mean damage per square mile following unrest }\end{array}$ & $\begin{array}{l}0.65 \\
16.7\end{array}$ & $\begin{array}{l}0.48 \\
28.9\end{array}$ & $\begin{array}{r}0.0-1.0 \\
0.0-250.7\end{array}$ & $\begin{array}{l}0.394 \neq \\
0.205 \neq\end{array}$ \\
\hline $\begin{array}{l}\text { Surrendered at least one off-premise outlet following } 1992 \text { civil unrest (binary) } \\
\text { Percentage of off-premise outlets that surrendered license in } 1992 \\
\text { Pre-riot (1991) number of off-premise outlets per road mile } \\
\text { Mean 1993-1996 post-riot off-premise outlets per road mile } \\
1990 \text { population }\end{array}$ & $\begin{array}{r}0.30 \\
10.3 \\
0.77 \\
0.74 \\
5502.8\end{array}$ & $\begin{array}{r}0.46 \\
19.2 \\
0.65 \\
0.65 \\
2146.0\end{array}$ & $\begin{array}{r}0.0-1.0 \\
0.0-100.0 \\
0.0-4.3 \\
0.0-5.1 \\
350.0-16416.0\end{array}$ & $\begin{array}{r}0.508 \neq \\
0.502 \neq \\
0.1278 \neq \\
0.143 \neq \\
-0.259 \neq\end{array}$ \\
\hline Road miles per census tract & 8.6 & 5.0 & $1.2-46.1$ & -0.046 \\
\hline
\end{tabular}

\footnotetext{
${ }^{\mathrm{a}} \mathrm{P}$-value $=\ddagger<0.0001 ; \dagger<0.01 ; \mathbb{S}<0.05 ; *<0.1 ;{ }^{\mathrm{b}} \mathrm{SES}=$ socio-economic status.
} 
tors, alcohol density and other covariates at baseline are presented in the furthest right-hand column of Table 1. All predictors were strongly correlated with the gonorrhea rate except for percentage male, percentage less than high school education and road miles per census tract. As previously shown, higher alcohol outlet density per roadway mile was associated with higher gonorrhea rates in both pre- and post-unrest periods. Social capital indicators were also significantly associated with gonorrhea rates. Tracts with more civic engagement had lower rates of gonorrhea, while tracts with a neighbourhood structure conducive to social organization had higher rates of gonorrhea at baseline.

The relationships between social capital on alcohol outlet density and age-gender adjusted gonorrhea rates over time are shown in Table 2. In a model with annual change in only alcohol outlet density (number off-premise outlets per road mile) and surrendered license status at the tract level (\% of licenses surrendered and the impact of surrendered licenses on gonorrhea rates over time), the average gonorrhea rate in1992 for tracts with no damage, with all continuous characteristics fixed at their overall mean (representing the "average" tract), was 165.5 per 100,000 (Table 2, panel 1). Tracts with increasing off-premise liquor outlet density experienced an increase in gonorrhea rate of 22.9 per 100,000 per year for each unit increase in outlet density. Tracts with more liquor outlets surrendered in 1992 had lower gonorrhea rates on average than tracts with fewer licenses surrendered (-4.1 per 100,000; $\mathrm{P}<0.05)$.

Adding indicators of social capital appeared to mediate the observed relationship between alcohol outlet density and gonorrhea rate. In model 2, adding percent voting rendered the estimate of alcohol outlet density insignificant, decreasing the effect of outlet density by 16.0 cases per 100,000 (95\% confidence interval $(\mathrm{CI})=6.9-22.9$, Table 2 panel 2). In model 3, positive neighbourhood structure (i.e., endogenous social organization) was significantly associated with gonorrhea rate and decreased the effect of density by 15.5 cases per 100,000 (95\% CI = 7.4-22.9; Table 2 panel 3). Results also reveal that tracts with greater voting over time and with greater endogenous social organization also experienced 1.9 and 67.2 fewer gonorrhea cases per 100,000, respectively.

Although not shown, the crude Moran's $I$ on the

Table 2. Predictors of age-gender adjusted gonorrhea rate (per 100,000) over time: results of unconditional linear growth models.

\begin{tabular}{|c|c|c|c|}
\hline Variables & $\begin{array}{l}\text { Model with } \\
\text { alcohol only }\end{array}$ & $\begin{array}{l}\text { Model with } \\
\% \text { voting }\end{array}$ & $\begin{array}{l}\text { Model with endogenous } \\
\text { social organization }^{\mathrm{a}}\end{array}$ \\
\hline$\beta$ (constant / intercept) & $165.5 \ddagger$ & $152.2 \ddagger$ & $174.4 \ddagger$ \\
\hline \multicolumn{4}{|l|}{ Time-level variables } \\
\hline $\begin{array}{l}\text { Year } \\
\% \text { Hispanic } \\
\% \text { African American } \\
\% \text { Age } 15-44 \text { years } \\
\% \text { Male } \\
\text { \# Off-premise outlets per road mile }\end{array}$ & $\begin{aligned}-83.5 & \ddagger \\
-1.7 & \ddagger \\
3.5 & \ddagger \\
-5.2 & \ddagger \\
10.7 & \neq \\
22.9 & \ddagger\end{aligned}$ & $\begin{array}{r}-88.1 \neq \\
-1.6 \ddagger \\
3.5 \neq \\
-5.1 \ddagger \\
9.7 \ddagger \\
6.9\end{array}$ & $\begin{aligned} &-58.3 \ddagger \\
&-0.9 \ddagger \\
& 3.3 \neq \\
&-6.4 \neq \\
& 8.4 \ddagger \\
& 7.4\end{aligned}$ \\
\hline$\%$ Voted & & $-1.9 \ddagger$ & \\
\hline \multicolumn{4}{|l|}{ Tract-level variables } \\
\hline $\begin{array}{l}\text { Baseline age-gender adjusted Gonorrhea rate (1990) } \\
\text { SES }(1990) \\
\text { \# Damaged properties per square mile } \\
\text { \% Off-premise licenses surrendered } \\
\text { Baseline \% voted (1990) }\end{array}$ & $\begin{array}{c}3.3 \neq \\
-50.1 \neq \\
0.1 \\
-4.1 \mathbb{S}\end{array}$ & $\begin{array}{r}3.6 \neq \\
-33.6 \neq \\
0.3 \\
-2.8 \\
-1.6\end{array}$ & $\begin{array}{r}3.4 \ddagger \\
-36.8 \dagger \\
0.2 \\
-2.3\end{array}$ \\
\hline Neighbourhood structure index score/endogenous social organization (1990) & & & $-67.2+$ \\
\hline $\begin{array}{l}\text { Akaike information criterion (AIC) } \\
\text { Moran's I }\end{array}$ & $\begin{array}{r}57022.6 \\
0.118\end{array}$ & $\begin{array}{r}46250.9 \\
0.077\end{array}$ & $\begin{array}{r}56268.9 \\
0.131 \\
\end{array}$ \\
\hline
\end{tabular}

${ }^{a}$ P-value $(2$-side $) \ddagger<0.001 ; \dagger<0.01 ; \mathbb{S}<0.05 ; *<0.1 ;{ }^{\text {b }} \mathrm{SES}=$ socio-economic status. 


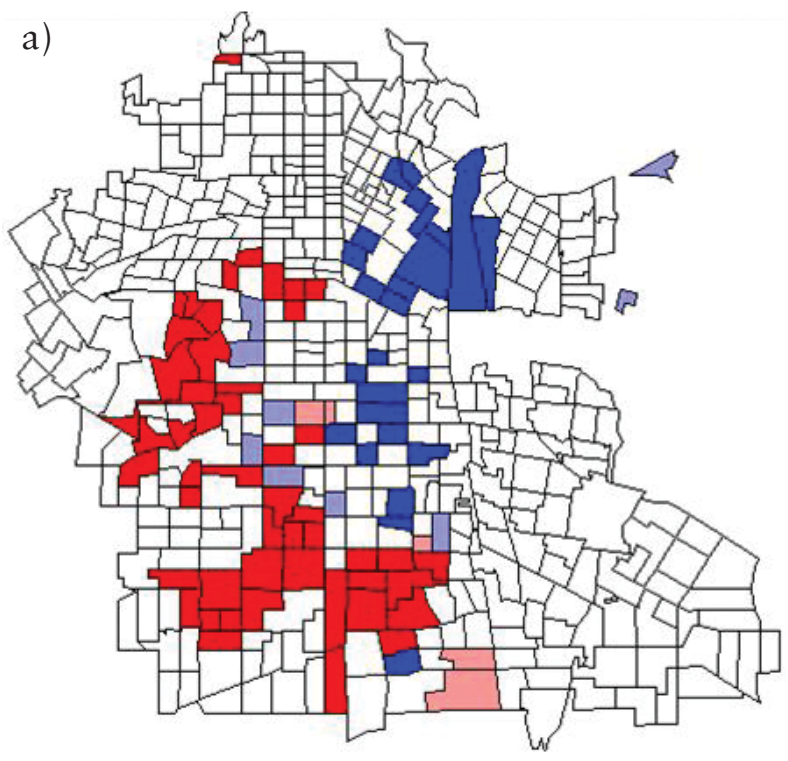

Fig. 2a. LISA map of crude model residuals of tract-level gonorrhea rates in the unrest area.

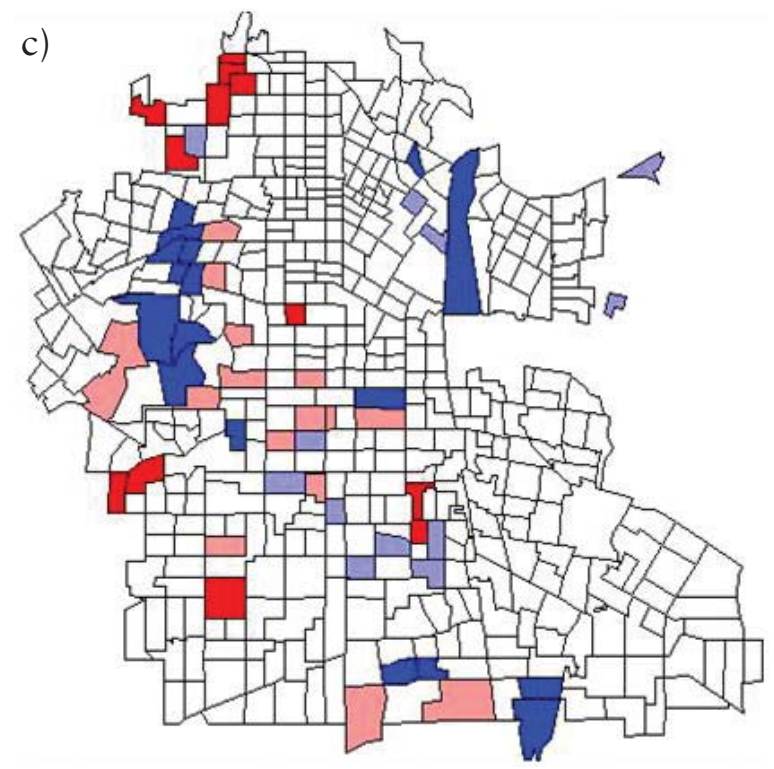

Fig. 2c. LISA map of adjusted model residuals of tract-level gonorrhea rates in the unrest area, adjusted for alcohol outlet density and other individual covariates and including percentage voting.

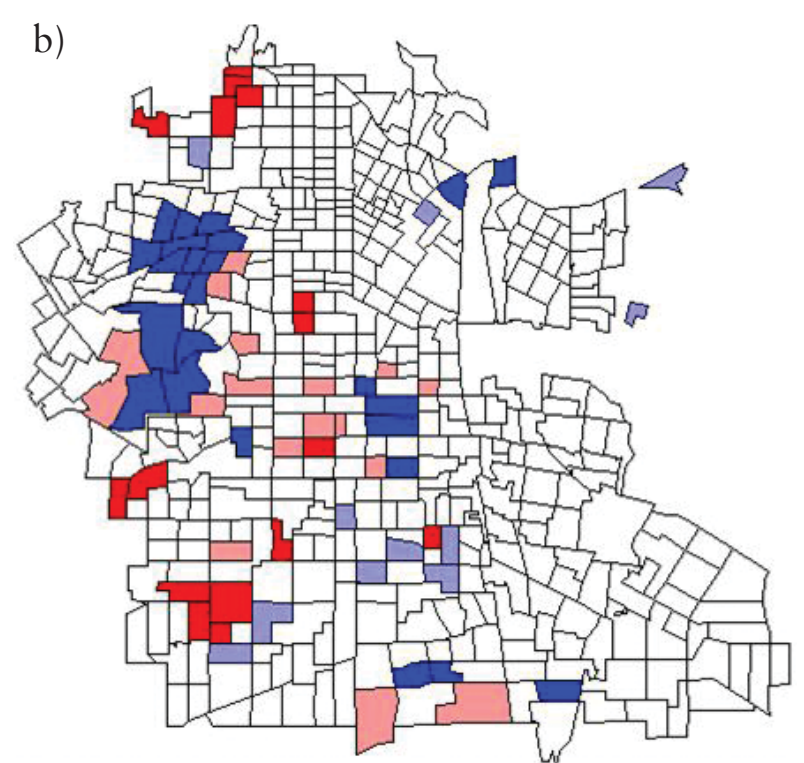

Fig. 2b. LISA map of adjusted model residuals of tract-level gonorrhea rates in the unrest area, adjusted for alcohol outlet density and other individual covariates.

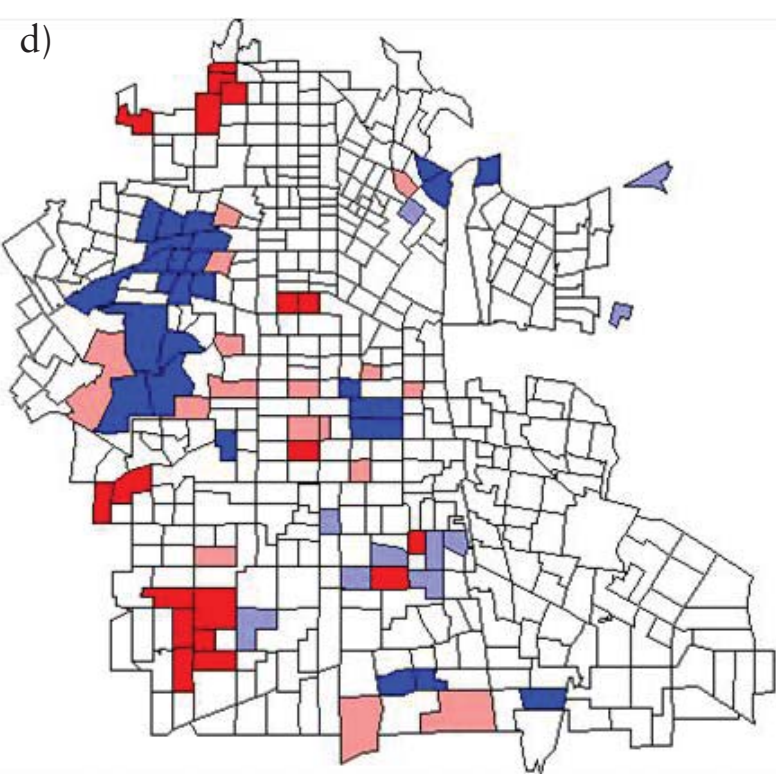

Fig. 2d. LISA map of adjusted model residuals of tract-level gonorrhea rates in the unrest area, adjusted for alcohol outlet density and other individual covariates and including endogenous social organization. 
residual of an empty regression model was 0.272. Clusters of elevated gonorrhea rates were seen in the southwest portion of the unrest area as shown in Figure 2a (in red, "High-High"). The addition of alcohol and other socio-demographic predictors explained a substantial amount of the residual spatial autocorrelation in gonorrhea rate (Moran's $I=0.118$, Table 2 , panel 1$)$. The addition of voting to model 1 also decreased the amount of residual spatial autocorrelation in gonorrhea rate (Moran's $I=0.077$ ), while the addition of endogenous social organization did little to improve the spatial autocorrelation when added to a model with alcohol and other socio-demographic factors. The reduction in variance explained is also evident in the LISA maps, shown in Figures $2 \mathrm{~b}-\mathrm{d}$, where clusters of high gonorrhea are greatly reduced or disappear with the addition of alcohol outlet density and indicators of social capital.

Table 3 presents the results of multivariate longitudinal models with the addition of the true impact of surrendered outlets on the change in gonorrhea rate over time (i.e. the interaction between percent surrendered and time). The rate of decline over time for tracts with more surrendered licenses was steeper than in tracts with fewer surrendered licenses, with 2.4 fewer cases per 100,000 per year for each percent increase in license surrender $(\beta=-2.4, \mathrm{P}$ $<0.001$, Table 3, panel 1). The rate of decline in gonorrhea cases over time according to surrendered

Table 3. Unconditional linear growth models with cross-level interactions included.

\begin{tabular}{|c|c|c|c|}
\hline Variables & $\begin{array}{l}\text { Model with } \\
\text { alcohol only }\end{array}$ & $\begin{array}{l}\text { Model with } \\
\% \text { voting }\end{array}$ & $\begin{array}{l}\text { Model with endogenous } \\
\text { social organization }^{\mathrm{a}}\end{array}$ \\
\hline$\beta$ (constant / intercept) & $165.5 \neq$ & $152.2 \ddagger$ & $174.4 \ddagger$ \\
\hline \multicolumn{4}{|l|}{ Time-level variables } \\
\hline $\begin{array}{l}\text { Year } \\
\% \text { Hispanic } \\
\% \text { African American } \\
\% \text { Age } 15-44 \text { years } \\
\% \text { Male } \\
\text { \# Off-premise outlets per road mile }\end{array}$ & $\begin{array}{r}-83.5 \neq \\
-1.7 \ddagger \\
3.5 \neq \\
-5.2 \ddagger \\
10.7 \ddagger \\
22.9 \dagger\end{array}$ & $\begin{array}{r}-88.1 \neq \\
-1.6 \dagger \\
3.5 \ddagger \\
-5.1 \dagger \\
9.7 \ddagger \\
6.9\end{array}$ & $\begin{array}{r}-58.3 \ddagger \\
-0.9 \ddagger \\
3.3 \ddagger \\
-6.4 \ddagger \\
8.4 \ddagger \\
7.4\end{array}$ \\
\hline$\%$ Voted & & $-1.9 \ddagger$ & \\
\hline \multicolumn{4}{|l|}{ Tract-level variables } \\
\hline $\begin{array}{l}\text { Baseline age-gender adjusted Gonorrhea rate (1990) } \\
\text { SES (1990) } \\
\text { \# Damaged properties per square mile } \\
\text { \% Off-premise licenses surrendered } \\
\text { Baseline \% voted (1990) }\end{array}$ & $\begin{aligned} & 3.3 \ddagger \\
&-50.1 \ddagger \\
& 0.1 \\
&-4.1 \mathbb{S}\end{aligned}$ & $\begin{array}{r}3.6 \neq \\
-33.6 \neq \\
0.3 \\
-2.8 \\
-1.6\end{array}$ & $\begin{array}{r}3.4 \ddagger \\
-36.8 \dagger \\
0.2 \\
-2.3\end{array}$ \\
\hline Neighborhood structure index score/endogenous social organization (1990) & & & $-67.2 \dagger$ \\
\hline \multicolumn{4}{|l|}{ Cross-level interaction } \\
\hline $\begin{array}{l}\% \text { Surrendered licenses x year } \\
\text { Baseline \% voted x year } \\
\text { Endogenous social organization x year }\end{array}$ & $-2.4 \ddagger$ & $\begin{array}{l}-2.3 \ddagger \\
-0.7 \ddagger\end{array}$ & $\begin{array}{l}-2.4 \ddagger \\
-13.4 \ddagger\end{array}$ \\
\hline $\begin{array}{l}\text { Akaike information criterion (AIC) } \\
\text { Moran's I }\end{array}$ & $\begin{array}{r}57022.6 \\
0.1175\end{array}$ & $\begin{array}{r}46250.9 \\
0.0767\end{array}$ & $\begin{array}{r}56268.9 \\
0.1306\end{array}$ \\
\hline
\end{tabular}

${ }^{\text {a }}$ P-value $=\ddagger<0.0001 ; \dagger<0.01 ; \mathbb{S}<0.05 ; *<0.1 ;{ }^{\text {b }}$ SES = socio-economic status. 
licenses, however, remained similar with the addition of all potential mediators.

The rate of gonorrhea decline over time was significantly steeper in tracts with greater baseline voting $(\beta=-0.7, P<0.001)$ and in those with greater levels of endogenous social organization at baseline $(\beta=-13.4, \mathrm{P}<0.001)$.

\section{Discussion}

In the present study, we examined (i) whether indicators of social capital were associated with neighbourhood gonorrhea rates, and (ii) whether the relationship between alcohol outlet density and gonorrhea rate is mediated in part by social capital indicators. Our results suggest that voting and social organization are associated with gonorrhea rates at the tract or neighbourhood level. Findings also reveal a positive mediating role of social capital, as measured by percent voting and endogenous social organization, on the relationship between alcohol outlet density and gonorrhea rate, with the strongest effect seen for endogenous social organization. Although the relationship between the neighbourhood alcohol environment and gonorrhea rate may be mediated by social capital, the impact of social capital indicators on the rate of decline in gonorrhea rate over time would suggest otherwise that alcohol environment may still have a direct role in infectious disease outcomes such as gonorrhea.

Off-premise outlets may influence gonorrhea rates by not only supplying alcohol (perhaps used for facilitating sex and possibly unprotected sex) but also through the situational risk they pose in the neighbourhood environment. Outlets are often sites where people who engage in high-risk behaviours gather, not just for drinking but sometimes to use and exchange other drugs. The closure of outlets therefore led not only to a decreased supply of alcohol, but also to fewer potential gathering places for high-risk individuals. Off-sale alcohol outlets are also associated with more social disorder, which is where social capital may come into play at the community level. Tracts with fewer outlets and more social cohesion may include people more willing to exert informal social controls, which could impact gonorrhea and other infectious disease transmission. However, it is also possible that independent events (e.g. targeted HIV and sexuallytransmitted disease prevention and control efforts, greater police presence and enforcement, curfew and other control measures) may have also contributed to tract-level gonorrhea rates by discouraging high-risk behaviours. If social capital as a construct reflects formal and informal reciprocal links among individuals in various types of networks, then perhaps it also leads to social support at the individual level with higher levels of social support (i.e. psychological resources) associated with lower levels of deviant behaviour and improved health (Kawachi and Berkman, 2000). However, our available data cannot speak to the potential impact of social capital at the individual level.

Societal, community and individual level components may influence gonorrhea rates, with behaviour associated with sexual disease transmission being shaped by, and occurring in a social context. With regard to prevention, there are different interventions that can be derived from models at the societal, community and individual levels (Lynch et al., 2000). Individual level programmes that promote social capital in poor, minority neighbourhoods may be protective against risky sexual behaviour. Crosby et al. (2002) found that African American adolescent females' membership in social organization was protective against their involvement in risky sexual behaviour. However, the complexity of a construct such as social capital and how it may impact behavior was shown recently by Campbell et al. (2002). In their South African study sample, the authors found that while membership in some types of community organizations was protective against HIV infections, membership in other groups was not. Despite the utility of individual prevention models, individual behaviour must be understood in a broader social context, where social, community and economic resources shape individual choices (Baum, 2000; Kawachi and 
Berkman, 2000).

At the community level, one prevention model is structural change within neighbourhoods. Environmental factors affecting alcohol availability have been shown to be effective preventive measures for a number of health outcomes, as shown with the impact of excise taxes (Chaloupka et al., 2002) minimum legal drinking age laws (Wagenaar and Toomey, 2002), and community organizing (Holder et al., 2000). Although changes in the physical environment are harder to elicit, they hold the promise of targeting interventions to specific neighbourhoods where health disparities are the greatest. Alcohol outlet density has yet to demonstrate a causal effect on alcohol-related outcomes primarily because it represents a measure of the physical environment and as such tests for causality must wait for a change in that environment (Cohen et al., 2000). Our findings support the importance of continuing controls and limits on alcohol outlet density, as a means of reducing gonorrhea rates (Cohen et al., 2006) and increasing social capital (Scribner et al., 2007). In the latter study, we found that removal of off-premise liquor outlets was associated with a subsequent increase in neighbourhood voting rates. Given available data, we could not determine the precise mechanism for this increase, although we hypothesize that one causal factor may have been the disruption of social networks which removed competing social networks (removing the negative networks associated with alcohol outlets and further fostering growth of the positive neighbourhood social networks).

Despite important findings and the strength of a longitudinal study design, limitations must be recognized. Data are ecological and therefore the complete picture of how societal, community and individual level factors may impact gonorrhea cannot be realized from our data. Nonetheless, the evolution of studies from purely ecologic studies at the neighbourhood level to multilevel studies of individuals nested within neighbourhoods confirms that many of the observed effects of neighbourhood socio-eco- nomic status may exist independent of individual risk (Diez-Roux et al., 1997). Recently multilevel studies have confirmed that the effect of alcohol outlets is independent of individual level risk factors (Scribner et al., 2000). Although annual data were available on race/ethnicity, gender and age of the denominator populations, and our models controlled for changes in the population. The use of only two indicators of social capital is also a limitation to this study. While voting data/civic engagement has been used by others as a key marker for social capital (Putnam, 2000), the construct itself is highly complex. The measure of social organization is also quite limited, only based on the 1990 census data, and may represent something other than a "potential" for social capital development (e.g. the number of adults per household may represent something other than available social support). Furthermore, data on the amount of damage per tract was only based on the 1992 estimates. If buildings were repaired right away, there was no way to account for this. The civil unrest changed both the physical and social structures of affected communities and it must be kept in mind that measures employed here do not capture all changes, some of which may also impacted gonorrhea rates.

Results support the importance of the local alcohol environment and social capital on neighbourhood level gonorrhea rates. It is possible that other outcomes may be affected as well, including crime and violence, injuries, mortality and other infectious diseases (e.g. HIV). Findings reveal the complexity of the concept of social capital and of the relationship between social capital, the neighbourhood environment and health outcomes and point to the need for additional research in this area.

\section{Acknowledgements}

This research was supported by NIAAA grant R01 AA013810-01A2. The views presented in this paper are those of the authors and do not represent those of the funding agencies. We wish to thank Sandy Johnson, Molly Scott and Angela Miu. 


\section{References}

Anselin L, 2005. Exploring spatial data with GeoDa: a workbook. Urbana, IL, Santa Barbara, CA. Center for Spatially Integrated Social Science. Spatial Analysis Laboratory, University of Illinois, Usa.

Baum F, 2000. Social capital, economic capital and power: further issues for a public health agenda. J Epidemiol Community Health 54, 409-410.

Bourdieu P, 1986. The forms of capital. In: The Handbook of Theory: Research for the Sociology of Education. JG Richardson (Ed), Greenwood Press, New York, USA, pp. 241-258.

Bursik RJ, 1988. Social disorganization and theories of crime and delinquency: problems and prospects. Criminology 26, 519-551.

Campbell C, Williams B, Gilgen D, 2002. Is social capital a useful conceptual tool for exploring community level influences on HIV infection? An exploratory case study from South Africa. AIDS Care 14, 41-54.

Carpiano RM, 2006. Toward a neighbourhood resourcebased theory of social capital for health: can Bourdieu and sociology help? Soc Sci Med 62, 165-175.

Cattell V, 2001. Poor people, poor places, and poor health: the mediating role of social networks and social capital. Soc Sci Med 52, 1501-1516.

Chaloupka FJ, Grossman M, Saffer H, 2002. The effects of price on alcohol consumption and alcohol-related problems. Alcohol Res Health 26, 22-34.

Cohen DA, Farley TA, Mason K, 2003a. Why is poverty unhealthy? Social and physical mediators. Soc Sci Med 57, 1631-1641.

Cohen DA, Ghosh-Dastidar B, Scribner R, Miu A, Scott M, Robinson P, 2006. Alcohol outlets, gonorrhea, and the Los Angeles civil unrest: a longitudinal analysis. Soc Sci Med 62, 3062-3071.

Cohen DA, Mason K, Bedimo A, Scribner R, Basolo V, Farley TA, 2003b. Neighbourhood physical conditions and health. Am J Public Health 93, 467-471.

Cohen DA, Scribner RA, Farley TA, 2000. A structural model of health behavior: a pragmatic approach to explain and influence health behaviors at the population level. Prev Med 30, 146-154.

Cohen DA, Spear S, Scribner R, Mason K, Kissinger P,
Wildgen J, 2000. Broken windows and the risk of gonorrhea. Am J Public Health 90, 230-236.

Coleman JS, 1990. Foundations of Social Theory. Harvard University Press, Cambridge, MA, USA.

Crosby R, DiClemente R, Wingood G, 2002. African American adolescent females' activity in social organizations: associations with HIV-protective behaviors. Ethn Dis 12, 186-192.

Diez-Roux AV, Nieto FJ, Muntaner C, Tyroler HA, Comstock GW, Shahar E, Cooper LS, Watson RL, Szklo M, 1997. Neighbourhood environments and coronary heart disease: a multilevel analysis. Am J Epidemiol 146, 48-63.

Evans C, 1993. Public health impact of the 1992 Los Angeles civil unrest. Public Health Rep 108, 265-272.

Freeman LC, 1992. Filling in the blanks: a theory of cognitive categories and the structure of social affiliation. Soc Psychol Q 55, 118-127.

Gorman DM, Speer PW, 1997. The concentration of liquor outlets in an economically disadvantaged city in the northeastern United States. Subst Use Misuse 32, 2033-2046.

Granfield R, Cloud W, 2001. Social context and "natural recovery": the role of social capital in the resolution of drug-associated problems. Subst Use Misuse 36, 15431570.

Gruenewald PJ, Ponicki WR, 1995. The relationship of the retail availability of alcohol and alcohol sales to alcoholrelated traffic crashes. Accid Anal Prev 27, 249-259.

Harpham T, Grant E, Thomas E, 2002. Measuring social capital within health surveys: key issues. Health Policy Plan 17, 106-111.

Holder HD, Gruenewald PJ, Ponicki WR, Treno AJ, Grube JW, Saltz RF, Voas RB, Reynolds R, Davis J, Sanchez L, Gaumont G, Roeper P, 2000. Effect of community-based interventions on high-risk drinking and alcohol-related injuries. JAMA 284, 2341-2347.

Holtgrave D, Crosby R, 2003. Social capital, poverty, and income inequality as predictors of gonorrhoea, syphilis, chlamydia and AIDS case rates in the United States. Sex Transm Infect 79, 62-64.

Hubler S, 2002. Extensive survey of riot area finds some surprises. Los Angeles Times, November 20, p. 1.

Kawachi I, Berkman L, 2000. Social cohesion, social capital, and health. In: Social Epidemiology. L Berkman and I Kawachi (Eds). Oxford University Press, New York, NY, 
USA, pp. 174-190.

Leyden KM, 2003. Social capital and the built environment: the importance of walkable neighbourhoods. Am J Public Health 93, 1546-1551.

Lindstrom M, 2005. Social capital, the miniaturization of community and high alcohol consumption: a populationbased study. Alcohol Alcohol 40, 556-562.

Littell R, Milliken G, Stroup W, Wolfinger R, 1996. SAS system for mixed models. SAS Institute Inc, Cary, NC, USA.

Lochner K, Kawachi I, Kennedy BP, 1999. Social capital: a guide to its measurement. Health Place 5, 259-270.

Lynch J, Due P, Muntaner C, Davey Smith G, 2000. Social capital-is it a good investment strategy for public health? J Epidemiol Community Health 54, 404-408.

Macintyre S, Ellaway A, Cummins S, 2002. Place effects on health: how can we conceptualise, operationalise and measure them? Soc Sci Med 55, 125-139.

Metro Chicago Information Center, 2005. Social capital component of the community vitality index (CVI). Accessed August 1, 2005.

MMWR, 2000. Alcohol policy and sexually transmitted disease rates-United States, 1981-1995. MMWR 49, 346-349.

Ong P, 1993. Losses in the Los Angeles civil unrest, April 29May 1, 1992: lists of the damaged properties and Korean merchants and the L.A. Riot Rebellion. UCLA, Los Angeles, USA.

Pickett KE, Pearl M, 2001. Multilevel analyses of neighbourhood socioeconomic context and health outcomes: a critical review. J Epidemiol Community Health 55, 111-122.

Poortinga W, 2006. Social capital: an individual or collective resource for health? Soc Sci Med 62, 292-302.

Putnam RD, 2000. Bowling alone: the collapse and revival of American community. Simon and Schuster, New York, USA.

Putnam RD, Leonardi R, Nanetti R, 1993. Making democracy work: civic traditions in modern Italy. Princeton University Press, Princeton, USA.

Robinson-Jacobs K, 2002. Replacing stores has lifted spirits. Los Angeles Times, p. C1.

Sampson RJ, 2003. The neighbourhood context of wellbeing. Perspect Biol Med 46, S53-64.

Sampson RJ, Groves WB, 1989. Community structure and crime: testing social-disorganization theory. Am J Sociol 94, 774-802.

Sampson RJ, Morenoff JD, Earls F, 1999. Beyond social cap- ital: spatial dynamics of collective efficacy for children. Am Sociol Rev 64, 633-660.

Sampson RJ, Morenoff J, Gannon-Rowley T, 2002. Assessing neighbourhood effects: social processes and new directions in research. Annu Rev Sociol 28, 443-478.

Sampson RJ, Raudenbush SW, 1999. Systematic social observation of public spaces: a new look at disorder in urban neighbourhoods. Am J Sociol 105, 603-651.

Sampson RJ, Raudenbush SW, Earls F, 1997. Neighbourhoods and violent crime: a multilevel study of collective efficacy. Science 277, 918-924.

Scribner RA, Cohen DA, Farley TA, 1998. A geographic relation between alcohol availability and gonorrhea rates. Sex Transm Dis 25, 544-548.

Scribner RA, Cohen DA, Fisher W, 2000. Evidence of a structural effect for alcohol outlet density: a multilevel analysis. Alcohol Clin Exp Res 24, 188-195.

Scribner RA, Cohen DA, Kaplan S, 1999. Alcohol availability and homicide in New Orleans: conceptual considrations for small area analysis of the effect of alcohol outle density. J Stud Alcohol 60, 310-316.

Scribner RA, MacKinnon DP, Dwyer JH, 1994. Alcohol outlet density and motor vehicle crashes in Los Angeles County cities. J Stud Alcohol 55, 447-453.

Scribner RA, Theall KP, Ghosh-Dastidar B, Mason K, Cohen D, Simonsen N, 2007. Structural determinants of social capital at the neighbourhood level: a longitudinal analysis of loss of alcohol outlets and voting. J Stud Alcohol Drugs 68, 934-943.

Singer J, 1998. Using SAS PROC MIXED to fit multilevel models, hierarchical models, and individual growth models. J Edu Behav Stat 24, 323-355.

Subramanian SV, Kim D, Kawachi I, 2005. Covariation in the socioeconomic determinants of self rated health and happiness: a multivariate multilevel analysis of individuals and communities in the USA. J Epidemiol Community Health 59, 664-669.

Subramanian SV, Lochner KA, Kawachi I, 2003. Neighbourhood differences in social capital: a compositional artifact or a contextual construct? Health Place 9, 33-44. Szreter S, Woolcock M, 2004. Health by association? Social capital, social theory, and the political economy of public health. Int J Epidemiol 33, 650-667.

Wagenaar AC, Toomey TL, 2002. Effects of minimum drink- 
ing age laws: review and analyses of the literature from 1960 to 2000. J Stud Alcohol 14, 206-225.

Weitzman ER, Chen YY, 2005. Risk modifying effect of social capital on measures of heavy alcohol consumption, alcohol abuse, harms, and secondhand effects: national survey findings. J Epidemiol Community Health 59, 303-309.
Woolcock M, Narayan D, 2000. Social capital: implications for development. Theory, research, and policy. World Bank Res Obs 15, 225-249.

Ziersch AM, Baum FE, Macdougall C, Putland C, 2005. Neighbourhood life and social capital: the implications for health. Soc Sci Med 60, 71-86. 